\title{
Aplicação do programa Seis Sigma no Brasil: resultados de um levantamento tipo survey exploratório-descritivo e perspectivas para pesquisas futuras
}

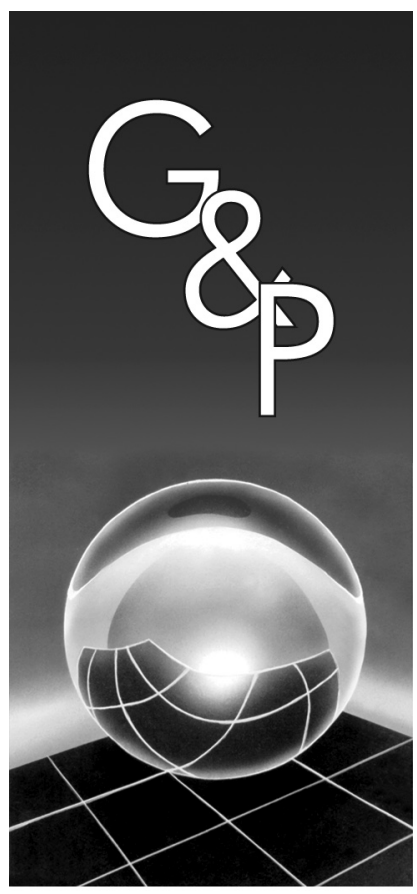

\author{
João Marcos Andrietta \\ Paulo Augusto Cauchick Miguel
}

Resumo

A utilização do Seis Sigma e das técnicas associadas ao programa tem possibilitado resultados que merecem uma avaliação mais detalhada, pois existem relativamente poucos dados publicados sobre a aplicação do Seis Sigma no país. Nesse sentido, o objetivo deste trabalho é apresentar os resultados de um estudo de campo do tipo survey exploratório-descritivo, conduzido com o propósito de levantar uma série de práticas relativas à adoção do programa Seis Sigma em empresas que o adotaram. $O$ instrumento de coleta de dados utilizado foi um questionário estruturado com uma taxa de retorno de aproximadamente 65\% dos 121 questionários enviados. Os resultados obtidos com o levantamento puderam revelar que a aplicação do Seis Sigma no Brasil é uma realidade. Contudo, o trabalho conclui que o programa é adotado por empresas de grande porte que investem em infra-estrutura e treinamento de pessoal, possibilitando obter os benefícios financeiros almejados. No final, o artigo considera perspectivas para trabalhos futuros, relacionadas à utilização das técnicas e ferramentas associadas à aplicação do programa, bem como os fatores de insucesso na sua utilização.

Palavras-chave: Seis Sigma. Gestão da qualidade. Melhoria da qualidade.

\section{Introdução}

O que atualmente se denomina Seis Sigma surgiu no início de 1987, quando profissionais da empresa Motorola iniciaram uma série de estudos sobre os conceitos estabelecidos por Deming sobre a variabilidade dos processos de produção, tendo como objetivo melhorar o desempenho por meio da análise de tais variações. Essas iniciativas foram reconhecidas pela direção da Motorola, que apoiou e estimulou a disseminação da nova abordagem proposta, pois visava à implantação em todas as atividades da empresa e enfatizava o conceito de melhoria contínua (HENDERSON; EVANS, 2000).

A proposta da Motorola buscava resolver o crescente aumento de reclamações relativas à ocorrência de falhas nos produtos eletrônicos manufaturados, dentro do período da garantia. Tal fato motivou a empresa a adotar o desafio de alcançar um desempenho de produtos livres de defeitos e tinha como alvos principais: o aumento da confiabilidade do produto final e a redução de perdas (SENAPATI, 2004). Em 1988, a Motorola recebeu o Prêmio Malcolm Baldrige de Qualidade e a introdução do programa Seis Sigma passou a ser reconhecida como responsável pelo sucesso alcançado pela organização. Após a divulgação dos ganhos obtidos pela Motorola, outras empresas adotaram o Seis Sigma, tais como (THEVNIN, 2004): Texas Instruments (em 1988), IBM (em 1990), ABB - Asea Brown Boveri (em 1993), Allied Signal e Kodak (em 1994) e a General Electric (em 1996).

Contudo, o caso de maior notoriedade na aplicação do Seis Sigma foi o da General Electric, que adotou o programa há cerca de 10 anos e, a partir de então, conseguiu considerável crescimento na margem do lucro operacional, conquistando a posição de uma das corporações mais bem sucedidas dos Estados Unidos, registrando depois de três anos uma economia de mais de US\$ 1,5 bilhões (BAÑUELAS; ANTONY, 2002).

No Brasil, o Seis Sigma foi disseminado a partir de 1997, quando o Grupo Brasmotor introduziu o programa em suas atividades e apurou em 1999 ganhos de R \$ 20 milhões (WERKEMA, 2002a). Contudo, existem poucos dados a respeito dos resultados obtidos com uma aplicação mais extensiva do programa Seis Sigma no país. Registram-se hoje dois levantamentos do gênero (WERKEMA, 2002b; FALANDO DE QUALIDADE, 
2004). Ambos os levantamentos, porém, apresentam limitações em virtude do reduzido número de empresas participantes e de uma análise restrita dos dados coletados.

Considerando que a utilização do Seis Sigma no Brasil é relativamente recente, o tema é relevante uma vez que a aplicação do programa tem possibilitado às empresas resultados e benefícios que merecem ser identificados e melhor compreendidos, foi elaborada uma pesquisa de campo tipo survey exploratória-descritiva (FORZA, 2002) com o propósito de ampliar o conhecimento sobre o uso do Seis Sigma no país. Mais especificamente, o objetivo deste trabalho é apresentar os métodos e técnicas aplicadas na elaboração e desenvolvimento do levantamento, analisar os resultados obtidos pelas respostas de questionários, bem como, sugerir algumas perspectivas para pesquisas futuras, no intuito de aprofundar o estudo sobre a aplicação do programa no território brasileiro.

\section{Referencial teórico sobre o Seis Sigma}

O princípio fundamental do programa Seis Sigma é reduzir continuamente a variação nos processos, e desta maneira eliminar os defeitos ou falhas nos produtos e serviços (LINDERMAN et al., 2003). Atualmente, o Seis Sigma é compreendido como uma prática de gestão, que busca melhorar a lucratividade de empresas de qualquer setor de atividade, sejam produtos ou serviços (HAHN et al., 2000) ou de qualquer porte - pequena, média ou grande empresa (WESSEL; BURCHER, 2004), com a finalidade de aumentar a participação de mercado, reduzir custos e otimizar as operações (BREYFOGLE III et al., 2001).

Assim, a implantação do programa nas organizações visa, de maneira estruturada, incrementar a qualidade por meio da melhoria contínua dos processos envolvidos na produção de um bem ou serviço, considerando todos os aspectos importantes de um negócio (PFEIFER et al., 2004). O Seis Sigma também prioriza o aumento da rentabilidade, pois o programa concentra grande esforço na redução dos custos da qualidade e no aperfeiçoamento da eficiência e da eficácia de todas as operações que visam atender as necessidades dos clientes (ANTONY; BAÑUELAS, 2001).

A aplicação do Seis Sigma ocorre com o apoio de uma série de ferramentas para a identificação, análise e solução de problemas, com acentuado embasamento na coleta e tratamento de dados, e com suporte estatístico (HONG; $\mathrm{GOH}, 2003)$. Assim, o diferencial do programa Seis Sigma reside na forma de aplicação estruturada dessas ferramentas e procedimentos e em sua integração com as metas e os objetivos da organização como um todo. Desta maneira, a participação e o comprometimento de todos os níveis e funções da organização é o fator-chave para o êxito da implantação do programa, além de outros fatores de extrema importância, tais como: o compromisso da alta administração, uma atitude pró-ativa dos envolvidos no programa, e sistematização na busca da satisfação das necessidades e dos objetivos dos clientes e da própria organização (BAÑUELAS; ANTONY, 2002). O Seis Sigma prioriza, ainda, a escolha criteriosa do pessoal que irá se envolver na implantação e aplicação do programa, bem como, o treinamento e a formação das equipes para a seleção, implementação, condução e avaliação dos resultados obtidos com os projetos executados, que são a base de sustentação do programa (INGLE; ROE, 2001).

\subsection{Implementação do programa Seis Sigma}

A fase mais importante do Seis Sigma é a sua implementação, pois existem aspectos que são essenciais no processo de inserção do programa nas organizações. Entre os principais fatores que podem assegurar a eficácia do Seis Sigma destaca-se o comprometimento da gerência com o programa, em virtude da necessidade da alocação de recursos que sustentem sua manutenção (GOH; XIE, 2004). Outro fator relevante é a mudança cultural, pois a implementação do Seis Sigma exige ajustes na cultura da organização e uma nova atitude dos funcionários que devem se sentir continuamente motivados para os desafios e o rigor que o programa impõe, em especial, no que se refere à coleta e mensuração dos dados dos processos (ANTONY, 2004).

Considera-se também como um fator decisivo na implementação do Seis Sigma, a necessidade de existir nas empresas uma infra-estrutura organizacional adequada e que assegure a introdução, desenvolvimento e continuidade do programa (WIPER; HARRISON, 2000). Um dos requisitos da infra-estrutura necessária para sustentar o Seis Sigma nas empresas é o treinamento dos funcionários envolvidos com o programa. A capacitação dos funcionários que se envolvem com o Seis Sigma utiliza uma prática distinta, pela qual são atribuídas denominações segundo a carga horária de treinamento, hierarquia nos projetos e dedicação de tempo ao programa (BEHARA et al., 1995). Nesse contexto, os profissionais envolvidos no Seis Sigma recebem terminologias específicas, tais como: sponsor que é o "número um" da organização relativo ao programa e tem a responsabilidade de promover e definir as diretrizes para a implementação do Seis Sigma; sponsor facilitador, que exerce as principais funções no desenvolvimento dos projetos do programa; champions, que são os gestores dos projetos e apóiam as ações ou removem possíveis barreiras na condução dos projetos. Depois, seguem os demais integrantes do Seis Sigma, que são diferenciados de acordo com níveis de conhecimento e capacitação, recebendo as seguintes denominações: black belts (faixas pretas), green belts (faixas verdes), yellows e white belts (faixas amarelas e brancas), que 
embora componham o chamado "chão-de-fábrica", são treinados nos fundamentos do Seis Sigma, em especial, sobre a utilização das ferramentas básicas que se aplicam às várias fases dos projetos (HAN; LEE, 2002).

Destaca-se também como um fator importante na implementação do programa Seis Sigma, a seleção e o gerenciamento dos projetos, pois a falta de habilidade na escolha e condução de um projeto pode consumir tempo e recursos que depois geram frustrações e insucessos (BAÑUELAS; ANTONY, 2004). A experiência dos especialistas em Seis Sigma evidenciou que existem três critérios para a seleção adequada dos projetos (RAISINGHANI et al., 2005): a) critérios para obtenção de lucros nos negócios, que avaliam o impacto no atendimento das exigências dos clientes, os ganhos financeiros e a identificação de competências na empresa para a execução dos projetos; b) critérios de viabilidade, que analisam os recursos exigidos, a complexidade e as técnicas e ferramentas disponíveis na empresa para a implantação dos projetos; e c) critérios de impacto organizacional, pelos quais são vislumbrados os eventuais benefícios que serão obtidos com a realização dos projetos.

Um outro aspecto que é de fundamental importância para a implementação do Seis Sigma nas empresas é entender e executar os métodos ou processos de melhorias aplicados no desenvolvimento do programa, tais como (PANDE et al., 2000; BAÑUELAS; ANTONY, 2004): M/PCpS (estudo de caracterização de processos e máquinas ou machine/process characterization study); DMAIC (define, measure, analyse, improve and control), DFSS (design for Six Sigma), dentre outros.

Além desses métodos ou processos de melhoria, a utilização das técnicas e ferramentas utilizadas no Seis Sigma, também são de grande importância, pois proporcionam ao programa o estudo e a compreensão das variáveis dos processos, asseguram a coleta de dados confiáveis, revelam indicadores para a tomada de decisões e favorecem a busca de soluções para os problemas que causam as inconstâncias nos processos (BYRNE; NORRIS, 2003). Portanto, a adoção dos métodos de melhorias para desenvolver o Seis Sigma e a utilização de técnicas e ferramentas são recomendadas para assegurar a conquista dos objetivos propostos e a sustentação do programa (MUNRO, 2000), conforme são destacados a seguir.

\subsection{Sustentação do programa Seis Sigma}

O programa Seis Sigma se sustenta graças a uma correta seleção dos projetos. Assim, o passo inicial para o desenvolvimento de um projeto é a compreensão dos CTQs (criticals to quality), que são as características críticas para a qualidade (BREYFOGLE III et al., 2001). Em seguida, é necessário escolher um dos métodos de solução de problemas que podem ser aplicados no programa, como por exemplo, (LYNCH et al., 2003): $\mathrm{M} / \mathrm{PCpS}$ (machine/process characterization study), que é um estudo para a caracterização e otimização de processos, visando eliminar a perda de tempo e dinheiro; DMAIC, que são as iniciais para as etapas: define (definir), measure (medir), analyse (analisar), improve (melhorar) e control (controlar), ou ainda o método DFSS (design for Six Sigma), DMADV (que contempla as fases: definir, medir, analisar, desenhar e verificar) ou também, a metodologia DMEDI (com as etapas: definir, medir, explorar, desenvolver e implementar). De todos os métodos de solução de problemas mencionados, o mais utilizado atualmente é o DMAIC, em virtude de contemplar cinco etapas que conseguem, na maior parte dos projetos Seis Sigma, estruturar a implantação, desenvolvimento e conclusão dos projetos selecionados (PANDE et al., 2000; KLEFSJÖ et al., 2001; BAÑUELAS; ANTONY, 2003; LYNCH et al., 2003; GUPTA, 2005).

Assim, o uso concomitante de um dos métodos de solução de problemas existentes e a escolha adequada das ferramentas e técnicas oferecem sustentação ao programa Seis Sigma nas empresas (BAÑUELAS; ANTONY, 2002; MALEYEFF; KRAYENVENGER, 2004). Portanto, o êxito de um projeto Seis Sigma se dá através da validade das análises relativas ao desempenho do processo, que depende da credibilidade dos dados coletados e da capacidade das ferramentas e técnicas mensurarem com exatidão o que se pretende avaliar (HENDRICKS; KELBAUGH, 1998). Apesar da identificação das ferramentas e técnicas usadas no programa Seis Sigma não ser novidade, sua abordagem de uso e a maneira como são aplicadas podem avalizar a sustentação do programa e permitir que os benefícios obtidos sejam perpetuados (McADAM; LAFFERTY, 2004).

\subsection{Benefícios do programa seis sigma}

Os benefícios do Seis Sigma são os principais atrativos que despertam o interesse das empresas pelo programa (KLEFSJÖ et al., 2001). Entretanto, para avaliar concretamente cada benefício obtido com a implantação do Seis Sigma são necessários levantamentos de dados por meio de pesquisas junto às empresas que aplicam o programa ou, que estas organizações evidenciem suas conquistas através de informações confiáveis, como balanços, cartas aos acionistas ou divulgação na imprensa especializada (HOERL, 1998).

Os principais benefícios da aplicação do programa Seis Sigma são (ARNHEITER; MALEYEFF, 2005; BLAKESLEE Jr.,1999; HAN; LEE, 2002; SNEE, 2000; YOUNG, 2001): a busca da melhoria contínua dos processos; a conquista da satisfação dos clientes através da melhor compreensão dos requisitos exigidos; o pleno entendimento das entradas críticas dos processos necessárias para responder as alterações nas exigências e 
especificações definidas; aprimoramento da qualidade; ganhos no fluxo do processo; aumento da produtividade; redução de tempos de ciclo; aumento da capacidade produtiva e da confiabilidade dos produtos; redução dos defeitos, dos custos, de desperdícios; a eliminação de atividades que não agregam valor ao processo; e a maximização dos lucros. Contudo, como afirmado anteriormente, cabe sempre a constatação da extensão dos ganhos obtidos. Assim, a seguir são apresentados alguns casos em que os benefícios com a implantação do Seis Sigma foram evidenciados.

O caso que ganhou maior visibilidade foi o da General Electric (EUA) que se tornou um benchmark no assunto, pois a empresa investiu US\$ 380 milhões na implementação do Seis Sigma, em 1996, e apurou a obtenção de ganhos da ordem de US\$1,5 bilhões dois anos depois (HENDERSON; EVANS, 2000). Outro caso que também ganhou destaque foi o da empresa Dow Chemicals (EUA) que em um curto espaço de tempo - apenas três anos obteve em 1999, US\$1,5 bilhões de ganhos, estimulando outras unidades do grupo a incorporarem o programa independente do produto fabricado ou da área funcional da empresa (MOTWANI et al., 2004).

No Brasil, o caso mais conhecido é o do Grupo Brasmotor, tanto por ter sido a primeira empresa com tecnologia nacional a aplicar o Seis Sigma no país, quanto por ter conseguido auferir em 1999 - dois anos após a implementação do programa - ganhos da ordem de R\$ 20 milhões (WERKEMA, 2002a).

\subsection{Levantamentos sobre a adoção do programa Seis Sigma}

Considerando-se a importância dos benefícios da introdução de um programa Seis Sigma, tanto para validar a utilização do programa, quanto para justificar os dados revelados na literatura, desenvolveu-se o presente trabalho, que resultou nos resultados que são apresentados mais à frente. Entretanto, antes de revelar esses resultados, convém apresentar as outras pesquisas que foram conduzidas no país (WERKEMA, 2002b; FALANDO DE QUALIDADE, 2004). A Tabela 1 sintetiza as pesquisas mencionadas.
Cabe ressaltar que tanto o levantamento de 2002 quanto o realizado em 2004 coletaram dados de um número reduzido de empresas que utilizam o Seis Sigma. Assim, os dois levantamentos realizados anteriormente tiveram limitações que restringiram a possibilidade de compreender melhor as características das empresas que utilizam o programa Seis Sigma no país. No caso do levantamento que foi realizado em 2004, por exemplo, foram obtidas informações de apenas 8 empresas. Além disso, considerando que, depois de 1999, após a divulgação do êxito obtido pelo Grupo Brasmotor com o Seis Sigma, o programa se tornou amplamente conhecido e até 2003 já estava difundido em muitas empresas brasileiras, tais como: Brahma, Belgo Mineira, Votorantim Cimentos, Votorantim Metais, GE Plastics, Maxion, Grupo Gerdau, ALL, Líder Táxi Aéreo, Nokia, Tupy Fundições, Fiat Automóveis, entre outras. O número de respondentes do levantamento mencionado foi pouco representativo e os resultados não possibilitaram uma definição consistente "[...] a fim de avaliar o uso Seis Sigma no Brasil [...]" (FALANDO DE QUALIDADE, 2004) como se comprometeu o trabalho.

Outro ponto de limitação dos levantamentos anteriores é que não estabeleceram nenhuma relação entre os dados coletados e a conclusão de outros autores que também estudaram - mesmo em outros países - aspectos similares aos que foram abordados nos questionários das pesquisas mencionadas, ainda que se justifique o caráter inédito do levantamento que foi realizado em 2002.

Vale mencionar também que o levantamento realizado em 2004 tem ainda uma limitação recorrente, pois não faz comparações com os resultados obtidos em 2002. Aliás, sequer menciona o trabalho de Werkema (2002b). Além disso, não faz quaisquer citações ou referências sobre publicações relativas ao tema.

As limitações apontadas nos levantamentos realizados em 2002 e 2004 motivaram e reforçaram a intenção de ampliar, por meio de um levantamento mais extenso, o conhecimento sobre a aplicação do programa Seis Sigma no país. Neste propósito, o trabalho foi conduzido com base nos métodos e técnicas de pesquisa, apresentados a seguir.

Tabela 1. Resumo das pesquisas realizadas sobre Seis Sigma no Brasil.

\begin{tabular}{ccccc}
\hline Pesquisa & Ano & Empresas respondentes & Instrumento de coleta de dados & Tipos de questões \\
\hline "Report Seis Sigma" & 2002 & 11 & Questionário via correio & 39 questões, sendo: \\
& & & & 17 do tipo aberta \\
& & & & 14 do tipo múltipla escolha \\
& & & & do tipo dicotômicas \\
& & & Questionário eletrônico & 22 do tipo tricotômicas \\
"A Realidade do Seis & 2004 & & & 17 do tipo resposta única \\
Sigma no Brasil" & & & & 5 do tipo escalar \\
\hline
\end{tabular}




\section{Métodos e técnicas adotados na presente pesquisa}

Os dados apresentados neste trabalho são resultados de um levantamento cujo objetivo é investigar o uso do Seis Sigma no Brasil. Como o estudo realizado visa compreender o comportamento de uma amostra relativamente grande inserida numa população utilizando-se um instrumento de coleta de dados, o levantamento caracteriza-se como do tipo survey (MALHOTRA; GROVER, 1998).

Considerando ainda, que este trabalho desenvolveu um levantamento em empresas que confirmaram a utilização do programa, e ainda pretendeu aferir se são válidas as informações divulgadas na literatura sobre os ganhos financeiros e demais indicadores de desempenho obtidos com o programa, a pesquisa tem a característica de uma survey exploratória-descritiva, pois segundo Forza (2002) este tipo de pesquisa tem por objetivo explicar ou prever a ocorrência de um fenômeno, testar uma teoria existente ou avançar no conhecimento de um determinado assunto. Quando a survey é de caráter exploratório busca tornar um fenômeno mais familiarizado e compreendido, como por exemplo - no caso deste trabalho - determinar os benefícios associados à adoção do Seis Sigma. Por outro lado, uma survey de característica descritiva tem como propósito verificar a distribuição de um fenômeno na população, como também foi a intenção no presente trabalho, que buscou constatar aspectos de utilização do programa (ganhos financeiros, número de projetos conduzidos, etc.).

De acordo com Forza (2002), uma survey exploratória-descritiva se aplica durante as etapas preliminares do estudo de um fenômeno, cujo o objetivo é antecipar a percepção sobre um dado tema e fornecer as bases para uma pesquisa mais aprofundada ou quando normalmente não existem modelos e nem conceitos a serem medidos em relação ao fenômeno de interesse, como melhor medi-lo ou como descobrir novas facetas do fenômeno em estudo. Ainda segundo o autor anterior, outra razão pela escolha de uma survey exploratória-descritiva é que este tipo de pesquisa pode também contribuir na descoberta ou fornecer evidências preliminares que associem os conceitos entre si e posteriormente ajudem a explorar o limite válido de uma teoria. A presente pesquisa, por meio do método e técnica escolhida oferece condições seguras para a compreensão e o avanço do conhecimento sobre a utilização do programa Seis Sigma no país.

\subsection{Seleção das empresas e coleta de dados}

A coleta de dados foi feita por meio de um questionário enviado para 121 empresas que confirmaram previamente (por telefone) a utilização do programa Seis Sigma em suas atividades organizacionais. $\mathrm{O}$ conjunto de empresas a ser estudado foi definido a partir da identificação de organizações que aplicam o programa, utilizando fontes variadas, tais como: revistas especializadas nas áreas de qualidade e gestão; participação em cursos e seminários sobre o Seis Sigma; busca nos sites de empresas, com a finalidade de confirmar se as mesmas aplicam o seis Sigma em suas atividades; levantamento junto às empresas de consultoria que prestam serviços na implementação do Seis Sigma; e consultas aos fóruns e entidades associativas que reúnem empresas que utilizam o programa, além de relatos de casos advindos da literatura.

Considerando a colocação anterior, o tipo de amostra utilizada neste trabalho se caracteriza como uma amostragem não aleatória intencional, pois neste tipo de amostra (não probabilística) a seleção dos elementos da população que podem compor a amostra depende - pelo menos em parte - do julgamento do pesquisador (MATTAR, 1996). $\mathrm{Na}$ elaboração desta pesquisa foi utilizado o critério do julgamento para selecionar a população, em virtude da convicção inicial dos pesquisadores de que as empresas contatadas eram fontes de informações confiáveis e precisas para integrarem a amostra. Levando em consideração também, que a presente pesquisa teve por objetivo abranger empresas que adotaram o programa Seis Sigma no país, a amostra não é probabilística, principalmente em virtude da abrangência pretendida e da limitação de recursos financeiros pela viabilidade operacional requerida para a conquista de resultados satisfatórios, conforme estabelecido por Aeker et al. (1995), em um levantamento dessa natureza. É importante destacar que o trabalho não pretendeu identificar quem eram os usuários do programa Seis Sigma, visando constatar a representatividade de empresas que operam no país em relação ao total de empresas, mas sim obter um panorama das empresas que adotaram o programa. Sendo assim, a população alvo é intencional sem, portanto, necessitar de cálculo de tamanho da amostra e margem de erro, não objetivando a extrapolação do resultado para todo o universo de empresas usuárias do programa.

\subsubsection{Instrumento para a coleta de dados}

Após a definição do tipo de amostra a ser empregada no trabalho, foi definido o instrumento para a coleta de dados. Optou-se por um questionário, devido à possibilidade da racionalização do tempo de preenchimento, por permitir a aplicação simultânea em determinada quantidade de empresas e por atingir maior abrangência territorial, além de assegurar o caráter de sigilo e oferecer privacidade para os respondentes preencherem a pesquisa sem riscos de constrangimentos. Esse desenvolvimento foi embasado em Mattar (1996). Desta maneira, foi elaborado um questionário do tipo estruturado não disfarçado, pelo qual o respondente tem prévio conhecimento dos objetivos da pesquisa, conforme definido por 
Marconi e Lakatos (1996). No presente levantamento, o questionário foi elaborado com uma redação objetiva, sendo utilizadas, preferencialmente, questões fechadas, pela facilidade de resposta e de tabulação.

O questionário também contemplou um glossário para expressar os termos técnicos utilizados. Quando ocorreu o emprego de siglas, os significados também foram disponibilizados. Houve, igualmente, um cuidado com a elaboração de instruções detalhadas buscando um correto preenchimento do questionário, por meio de dois recursos: um quadro ilustrativo com uma simbologia visual e uma relação de explicações para cada um dos tipos de questões existentes no instrumento. Todos esses cuidados visaram uma elaboração satisfatória do questionário, com a finalidade de promover maior motivação aos respondentes e assim aumentar a taxa de retorno do levantamento.

As perguntas do questionário foram agrupadas e ordenadas em três blocos, a saber:

a) dados da empresa (com 6 questões englobando: o setor de atividade; principais produtos; número de funcionários; faturamento anual em milhões de reais; market share - mercado interno e externo; e a participação da empresa no principal mercado de atuação);

b) programa Seis Sigma (com 27 questões, abrangendo: o histórico do programa na organização; estrutura e formação de pessoal; número, escopo e critérios para seleção dos projetos desenvolvidos; a proporção entre projetos nas áreas produtiva e administrativa; planejamento para a implantação do Seis Sigma; e os principais resultados alcançados com o programa); e

c) integração das técnicas e ferramentas no programa Seis Sigma, que buscou identificar quais são as técnicas, métodos e ferramentas utilizadas em empresas que aplicam o programa (a partir de uma tabela para ser assinalada, com a relação de 58 ferramentas e técnicas). Cabe destacar ainda que o questionário procurou seguir uma lógica para preenchimento, iniciando com perguntas simples e gerais, e terminando com perguntas mais complexas e específicas, como é sugerido por Mattar (1996).

\subsection{Cuidados para melhorar a taxa de retorno e análise dos dados}

Conforme citado anteriormente e recomendado por Marconi e Lakatos (1996), algumas precauções e cuidados para melhorar o índice de retorno na presente pesquisa também foram adotados, tais como: contato prévio (via telefone) com os potenciais respondentes assegurando seu interesse e disponibilidade para participar do levantamento; envio de uma carta anexa ao questionário, explicando os objetivos da pesquisa; envio de envelope endereçado e com porte postal pago para a devolução do questionário; contatos periódicos por telefone e correio eletrônico com os respondentes (ao longo da pesquisa foram feitos, em média, 500 contatos com cerca de 140 empresas).

Após o retorno dos questionários, estes foram verificados, codificados e tabulados. A tabulação foi feita em planilhas do aplicativo Windows ${ }^{\circledR}$ Excel seguindo-se a mesma seqüência dos agrupamentos e blocos contidos no questionário, com o propósito de manter a lógica dos objetivos pretendidos pelas questões, conforme é recomendado por Malhotra (2001). Os dados foram calculados e expressos em percentuais e, com as tabulações, foram elaborados os gráficos que serviram para a análise posterior dos resultados obtidos com base na literatura e que são apresentados a seguir.

\section{Resultados da pesquisa - apresentação e discussão}

Os resultados deste levantamento foram obtidos por meio da devolução de 83 questionários $(68,7 \%)$ dos 121 que foram enviados. $\mathrm{Na}$ verdade, retornaram 78 questionários efetivamente respondidos, atingindo uma taxa de retorno útil de $64,5 \%$, pois havia a possibilidade de devolução do questionário em branco. Visando identificar a localização das 78 empresas respondentes, estas se encontram nos seguintes estados: Amazonas (5), Bahia (2), Ceará (1), Espírito Santo (1), Minas Gerais (7), Paraíba (1), Pernambuco (1), Rio de Janeiro (3), Rio Grande do Sul (4), Santa Catarina (3) e São Paulo (50). A caracterização das empresas é destacada a seguir. A distribuição geográfica dos respondentes no país foi bastante similar ao total de empresas identificadas para as quais o questionário foi enviado.

\subsection{Caracterização das empresas pesquisadas}

O levantamento de dados buscou também identificar o setor de atividade econômica das empresas respondentes. A classificação setorial seguiu o critério da revista Exame (2005). O perfil dos respondentes apontou que o setor automotivo destaca-se com um percentual de $37 \%$ e, em seguida, o setor eletroeletrônico, com cerca de $19 \%$. Outros segmentos industriais indicaram percentuais menores (siderurgia e metalurgia com 11,5\%; mecânica com 7,7\%; química e petroquímica com $6,4 \%$; e outros ramos tais como, material de construção com 5,1\%; plástico e borracha, farmacêutico, higiene e cosméticos, ambos com 3,8\%; papel e celulose, e telecomunicações com 2,6\%). Não obstante, notou-se uma proporção razoável de setores diversos e relativamente proporcionais à distribuição dos questionários enviados.

Com base nos índices mencionados anteriormente, ou seja, principalmente pela taxa de retorno e a quantidade 
de empresas respondentes, e também a diversidade de setores industriais que subsidiaram os resultados apresentados neste levantamento, pode-se apontar que os resultados são significativos com certa representatividade em relação ao universo analisado. No entanto, essa afirmação sobre a distribuição nos setores industriais não tem a intenção de generalização dos resultados.

Assim sendo, a caracterização das empresas respondentes revelou que a adoção do Seis Sigma, em organizações nos mais diferentes setores de atividades econômicas, está em conformidade com a literatura (ANTONY; BAÑUELAS, 2002; HAHN et al., 2000; HENDERSON; EVANS, 2000; LINDERMAN et al., 2003), ou seja, que o programa Seis Sigma pode ser aplicado em organizações de natureza diversa, independentemente do segmento industrial que a organização atua.

O levantamento possibilitou também traçar o perfil das empresas quanto ao porte. A classificação seguiu os critérios do PNQ - Prêmio Nacional da Qualidade (FNQ, 2004), segundo o número de funcionários: empresas com até 50 funcionários foram consideradas como pequenas; de 51 a 500 como médias; e mais de 500 como grandes. Quanto a esse critério, os dados coletados constataram que $65,4 \%$ são de grande porte e $34,6 \%$ são empresas médias. Cabe ressaltar que apesar da literatura indicar que o Seis Sigma pode ser utilizado por empresas de qualquer tamanho (MARASH, 2000; FOLARON, 2003; PFEIFER et al., 2004; WESSEL; BURCHER, 2004), os dados obtidos neste levantamento não revelaram a presença de empresas de pequeno porte. Isso também pode ser explicado pela composição do conjunto de empresas do levantamento.

Outro dado obtido pelo levantamento apontou o perfil das empresas quanto aos valores de faturamento previstos (ano base de 2004) expressos em milhões de reais. Foi possível constatar, que as empresas pesquisadas indicaram valores de faturamento anual variando de 33 milhões a 18 bilhões. Levando-se em conta o ranking da revista Exame (2005), mais de 60\% das empresas respondentes estão entre as 500 maiores em faturamento no Brasil. Além desses dados, o levantamento identificou também, que $41 \%$ dos respondentes se posicionaram como líderes no seu principal mercado de atuação.

Na seqüência das perguntas do questionário, os respondentes se detiveram nas questões que abordaram aspectos específicos relativos à implementação do programa Seis Sigma nas empresas. O objetivo de tais perguntas foi definir o histórico, os motivos e a forma de implantação do programa. Esses resultados são apresentados a seguir.

\subsection{Dados relativos à implementação do programa Seis Sigma}

O levantamento buscou identificar o ano de introdução do programa Seis Sigma nas empresas. Nota-se na
Figura 1 um pico na adoção do programa no ano 2000. Comparando-se os períodos de 1995 a 1999 e 2000 a 2003, percebe-se que nos quatro últimos anos houve um crescimento superior a $100 \%$ na adoção do programa Seis Sigma no país. A provável justificativa para o crescente aumento de empresas que adotaram o programa no país a partir do ano 2000 pode estar relacionada com os ganhos obtidos pelo Grupo Brasmotor (WERKEMA, 2002a) e pelos resultados conseguidos pela General Electric nos Estados Unidos, que motivaram a disseminação do programa em outras unidades da corporação e que acabaram se estendendo também nas plantas instaladas em outros países (HENDERSON; EVANS, 2000), como é o caso do Brasil onde a corporação possui várias unidades de negócios, que responderam o questionário.

Outro dado apurado pelo levantamento indicou que a identificação da necessidade da implantação do programa Seis Sigma surgiu, em quase três quartos dos casos, como uma "estratégia da empresa", em mais de 50\%, como uma "decisão da matriz", e aproximadamente $2,5 \%$ das empresas relacionaram a necessidade da adoção do Seis Sigma devido à "propaganda na imprensa". O motivo pelo qual a maioria dos respondentes apontou a "estratégia da empresa" como a principal necessidade da implantação do programa Seis Sigma em suas atividades, se justifica, pois vários autores (BANUELAS; ANTONY, 2002; BREYFOGLE III et al., 2001; ECKES, 2001; HAHN et al., 2000; KLEFSJO et al., 2001; LINDERMAN et al., 2003) defendem que o Seis Sigma é compreendido pelas empresas como uma estratégia gerencial disciplinada que tem como meta principal aumentar a lucratividade das empresas, baseando-se na relação existente entre projeto, fabricação, qualidade final, e entrega de um produto com a satisfação dos clientes.

\subsubsection{Implantação do programa}

No que se refere à identificação da necessidade de implantação do Seis Sigma nas empresas, comparando-se os dados obtidos neste trabalho com um trabalho anterior

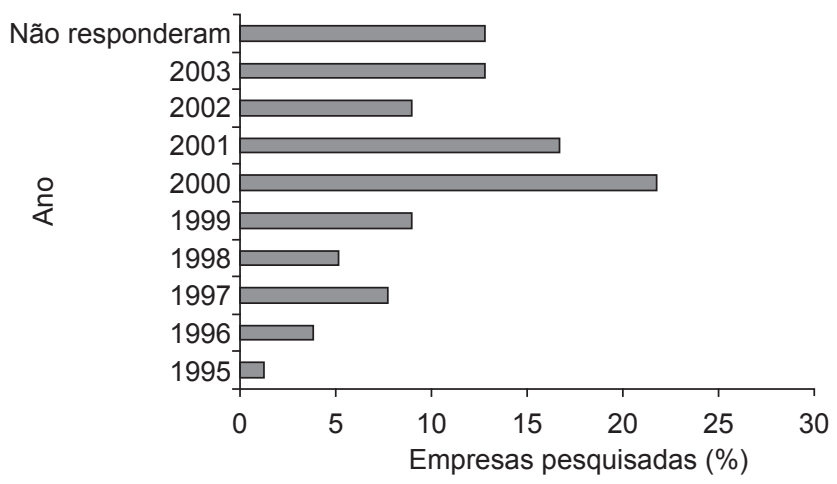

Figura 1. Data da introdução do programa Seis Sigma nas empresas pesquisadas. 
(WERKEMA, 2002b), constata-se uma similaridade, pois as duas causas mais indicadas pelos respondentes para implantar o programa foram, respectivamente, "estratégia da empresa" e "decisão da matriz". Os resultados do levantamento indicaram também que, em relação à forma de implantação do Seis Sigma, na maioria dos casos, ocorre com o "suporte da matriz", como é mostrado na Figura 2. Isso pode ser explicado, segundo Henderson e Evans (2000), pela razão de que o sucesso conquistado na matriz das empresas que adotaram o Seis Sigma estimula a divulgação do programa em outras unidades das corporações, através de processos de benchmarking interno.

Vale esclarecer, que a opção apontada por algumas empresas respondentes de que a implementação do Seis Sigma pode se dar também pela "auto-implantação" está apoiada no fato de que atualmente existem cursos de capacitação para os profissionais que se envolvem com o programa (INGLE; ROE, 2001; WIPER; HARRISON, 2000), além da existência de associações que congregam as empresas que utilizam o Seis Sigma, congressos e fóruns específicos sobre o assunto. A soma desses fatores pode qualificar as empresas para auto-implantarem o programa em suas atividades e também justificar o surgimento de "outras" formas de implantação, como demonstrado no gráfico da Figura 2.

O levantamento também procurou identificar quais foram as áreas da empresa que deram início ao estudo de implantação do programa Seis Sigma. Os dados revelaram que as áreas predominantes foram: a alta administração e a área da qualidade. Cabe destacar que, em diversas empresas, o estudo para implantação do Seis Sigma ocorreu em várias áreas ao mesmo tempo. Estes dados foram evidenciados, pois mais de uma área poderia ser assinalada na questão. Assim, quase $20 \%$ das empresas respondentes apontaram que, na fase de implantação, o programa foi adotado por mais de uma área.

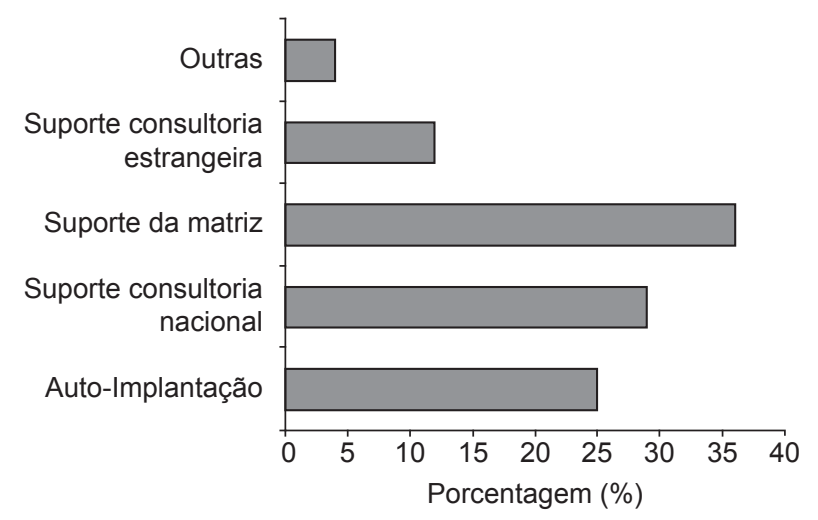

Figura 2. Forma de implantação do programa Seis Sigma nas empresas pesquisadas.
No tocante à identificação das áreas da empresa que deram início ao estudo de implantação do Seis Sigma, também se constatou similaridade entre os resultados obtidos no presente trabalho com o levantamento anterior (WERKEMA, 2002b), pois as duas áreas mais apontadas pelos respondentes para implantar o programa foram, respectivamente, "alta administração" e "qualidade". Apesar do início da implantação do Seis Sigma ter ocorrido em áreas definidas, nas empresas pesquisadas, o levantamento também indagou aos respondentes sobre quais áreas da empresa o programa Seis Sigma estava sendo aplicado efetivamente. Os dados revelaram que a aplicação do programa ocorre, em mais de $70 \%$ dos casos, "em toda empresa", ficando as áreas de "manufatura" com mais de $20 \%$ e a de "engenharia" com mais de $10 \%$. Cabe ressaltar que nas empresas pesquisadas, a área "financeira" é a que menos utiliza o programa (pouco mais de 1\%). Esse maior percentual pode ser atribuído à introdução do programa num primeiro momento nessas áreas. Além disso, as ferramentas de coleta e análise de dados, geralmente ministradas nos treinamentos, também são típicas dessas áreas, principalmente da manufatura. Para a área de finanças, outras ferramentas como séries temporais, análise de risco, dentre outras, geralmente não fazem parte do currículo dos treinamentos. Segundo Motwani et al. (2004), os projetos Seis Sigma podem ter origem em quaisquer áreas da empresa, como por exemplo: compras, vendas, finanças, materiais ou manufatura. $\mathrm{O}$ presente levantamento também buscou obter informações sobre a seleção e capacitação dos profissionais envolvidos no programa, como apresentado a seguir.

\subsection{Seleção dos especialistas no programa Seis Sigma}

No que se refere à seleção dos especialistas envolvidos no programa Seis Sigma, o principal critério citado por mais de $75 \%$ das empresas foi a "indicação". Como se tratava de uma questão de múltipla escolha, na qual as empresas poderiam apontar também outras possibilidades de seleção dos candidatos, mereceram destaque: o "plano de carreira", com quase $40 \%$ e "entrevista de seleção", com mais de $20 \%$. Destaca-se que o "voluntariado" também está presente, em mais de $15 \%$ dos casos, além de "testes de aptidão", em mais de $10 \%$. O resultado obtido confirma a posição de vários autores (HAHN et al., 2000; HENDRICKS; KELBAUGH, 1998; HOERL, 2001; INGLE; ROE, 2001) sobre o assunto, pois afirmam que a escolha de um candidato a especialista do seis sigma (master black belt, black belt ou green belt) deve ser criteriosa e partir de uma indicação (ou recomendação) dentro da própria organização, sempre respaldada pelo histórico e performance do profissional, em virtude dos riscos que uma escolha mal sucedida pode ocasionar. 
Isso se deve ao fato de que nestes profissionais são investidos recursos significativos em treinamento, além da responsabilidade que é atribuída na função, visando o pleno êxito dos projetos.

O levantamento buscou identificar também se após o processo de seleção dos profissionais envolvidos no Seis Sigma havia a escolha de coordenadores específicos para a condução do programa. Os resultados mostraram que mais de $93 \%$ das empresas designam um profissional para implementar o Seis Sigma. Esta verificação também tem similaridade com a pesquisa realizada anteriormente por Werkema (2002b), quando todas as empresas pesquisadas afirmaram a alocação de um coordenador específico para implantar o programa Seis Sigma. A justificativa para a verificação da existência de profissional dedicado exclusivamente ao processo de implementação do programa na quase totalidade das empresas respondentes se deve ao fato de que as empresas desejam evitar fracassos, pois a maioria dos projetos Seis Sigma falham devido à pouca habilidade no gerenciamento, configuração e manutenção das regras base e das responsabilidades atribuídas nos projetos (ANTONY; BAÑUELAS, 2001).

A seguir são apresentados os resultados obtidos no levantamento sobre a formação destes profissionais.

\subsubsection{Formação dos profissionais envolvidos com o programa Seis Sigma}

O levantamento teve a pretensão de identificar a presença e a quantidade de profissionais envolvidos diretamente com o programa, nas empresas respondentes. Considerando que uma questão foi dedicada exclusivamente à identificação de coordenadores específicos ao programa, optou-se por indagar apenas sobre a presença das três qualificações mais conhecidas (pelas publicações) e ligadas ao programa: master black, black e green belts. Os dados obtidos revelaram que os master black belts estão presentes em quase $40 \%$ das empresas pesquisadas, os black belts em cerca de $80 \%$ e os green belts em mais de 50\%, como detalha a Tabela 2.

Os dados obtidos no levantamento revelaram que as empresas respondentes possuem em seus quadros uma quantidade de profissionais envolvidos com o programa Seis Sigma, que estão abaixo dos padrões indicados por alguns autores (HOERL, 2001; INGLE; ROE, 2001; PEREZ-WILSON, 1999). A literatura recomenda que nas grandes empresas existam no mínimo 30 master black belts, pelo menos 1 black belt para cada 100 funcionários e 1 green belt para cada 20. Portanto, considerando que este levantamento apontou que mais de $65 \%$ das empresas respondentes são de grande porte, o número de profissionais envolvidos com o Seis Sigma é inferior ao recomendado. Por exemplo, em uma das empresas respondentes - de grande porte (com mais de 10 mil funcionários) - havia apenas 1 master black belt, e a proporção é de 1 black belt para cada 250 funcionários e 1 green belt para cada 100.

Contudo, o tempo médio de treinamento destinado aos profissionais envolvidos com o programa Seis Sigma apontou indicadores melhores quando comparados com a literatura. A pesquisa revelou que mais de $20 \%$ das empresas respondentes investem até 200 horas no aprimoramento dos master black belts, quase $65 \%$ reservam aos black belts de 201 a 400 horas de treinamento, e mais de $80 \%$ das empresas pesquisadas também dedicam até 200 horas ao aperfeiçoamento dos green belts, conforme está sintetizado na Tabela 3. Os resultados coincidem com

Tabela 2. Número de profissionais envolvidos com o programa Seis Sigma.

\begin{tabular}{ccccccr}
\hline $\begin{array}{c}\mathbf{N}^{\circ} \text { de profissionais } \\
\text { nas empresas respondentes }\end{array}$ & Master black belts & $\%$ & Black belts & \% & Green belts & \% \\
\hline Nenhum & 46 & 59,0 & 7 & 9,0 & 7 & 9,0 \\
De 1 a 50 & 29 & 37,2 & 62 & 79,5 & 41 \\
De 51 a 100 & 0 & 0,0 & 6 & 7,7 & 15 \\
De 101 a 150 & 0 & 0,0 & 0 & 0,0 & 10 \\
De 151 a 200 & 0 & 0,0 & 0 & 0,0 & 19,2 \\
Acima de 200 & 0 & 0,0 & 0 & 0,0 & 4 \\
Não responderam & 3 & 3,8 & 3 & 3,8 & 0 \\
\hline
\end{tabular}

Tabela 3. Treinamento dos profissionais envolvidos com o programa Seis Sigma.

\begin{tabular}{ccccccc}
\hline Carga horária de treinamento & Master black belts & \% & Black belts & \% & Green belts & \% \\
\hline Nenhuma & 46 & 59,0 & 7 & 9,0 & 5 & 6,4 \\
De 1 a 200 horas & 18 & 23,1 & 12 & 15,4 & 63 & 80,8 \\
De 201 a 400 horas & 14 & 17,9 & 50 & 64,1 & 5 & 6,4 \\
De 401 a 600 horas & 4 & 5,1 & 17 & 21,8 & 2 & 2,6 \\
Acima de 600 horas & 3 & 3,8 & 3 & 3,8 & 2 \\
\hline
\end{tabular}


as indicações de alguns autores (WIPER; HARRISON, 2000; HOERL, 2001; INGLE; ROE, 2001), que sugerem como tempo de treinamento ideal para os profissionais envolvidos no programa Seis Sigma, cerca de 200 horas. Esta constatação indica outro aspecto positivo do Seis Sigma, em especial nas empresas que aplicam o programa no Brasil, pois conforme os dados obtidos através deste levantamento, a carga horária de treinamento dos black e green belts é relativamente a mesma das empresas que adotaram o programa Seis Sigma em outros países, como no caso do trabalho de Hoerl (1998).

Vale registrar que os dois levantamentos realizados anteriormente abordaram de maneiras diferentes a questão do treinamento dos profissionais envolvidos no programa Seis Sigma. Um dos levantamentos (WERKEMA, 2002b) apurou a questão em dias de treinamento e obteve que as empresas respondentes dedicavam de 15 a 21 dias para a realização dos cursos de capacitação dos profissionais, ou seja, de 120 a 170 horas. O outro levantamento (FALANDO DE QUALIDADE, 2004) não conseguiu exprimir dados concretos com os resultados obtidos.

O presente levantamento também teve o propósito de identificar se os profissionais envolvidos no Seis Sigma oferecem dedicação exclusiva ao programa. A Tabela 4 aponta, que em quase $35 \%$ das empresas, os master black belts tem dedicação exclusiva e, em um pouco mais de $25 \%$ das empresas os black belts se dedicam exclusivamente ao Seis Sigma.

Cabe registrar que os resultados obtidos neste levantamento divergem de um dos que foram realizados anteriormente (WERKEMA, 2002b), que apurou cargas de dedicação dos profissionais envolvidos no Seis Sigma mais elevadas, como por exemplo: $100 \%$ dos master black belts; $60 \%$ dos black belts; e $35 \%$ dos green belts se dedicam exclusivamente ao programa. Tais constatações mostram realidades diferentes, inclusive da que foi apresentada por Hoerl (2001), que afirma que os black belts devem ter o tempo dedicado integralmente aos projetos Seis Sigma. Mesmo assim, o presente trabalho não conseguiu detectar quaisquer implicações - se positivas ou negativas - no tocante à dedicação dos profissionais do Seis Sigma.

\subsubsection{Reconhecimento aos profissionais envolvidos com o programa}

No que se refere ao reconhecimento concedido aos profissionais envolvidos no programa Seis Sigma, o levantamento constatou que mais de $50 \%$ das empresas pesquisadas oferecem algum tipo de recompensa aos especialistas que executam seus trabalhos na aplicação do programa. Essa concessão, que é oferecida aos master black belts, black belts e green belts, é prática comum nas empresas que adotam o Seis Sigma (HOERL, 2001), pois, em geral, os projetos executados buscam metas financeiras e o reconhecimento, tanto econômico quanto por mérito, e visa estimular os envolvidos na execução dos projetos (BARNEY, 2002).

Os dados coletados indicaram também, que em mais de $50 \%$ das empresas pesquisadas, são concedidos como reconhecimento ao empenho dos profissionais envolvidos no programa Seis Sigma, um "impulso na carreira", e em cerca de $30 \%$ dos casos, uma "premiação (não financeira)". Esses resultados confirmam as argumentações de outros autores (HENDRICKS; KELBAUGH, 1998; THEVIN, 2004), pois afirmam que quando os projetos Seis Sigma são apoiados em profissionais estimulados por algum tipo de recompensa previamente revelada, a possibilidade dos objetivos serem atendidos é bastante superior. Esta afirmação também foi demonstrada na pesquisa realizada por Harry e Schroeder (2000), que apontou em seus estudos que $61 \%$ das empresas indicaram uma ligação das recompensas concedidas aos profissionais envolvidos no programa Seis Sigma às suas estratégias de negócios.

\subsection{Aplicação do programa Seis Sigma e seus resultados}

Um dos principais objetivos do levantamento foi buscar a obtenção de dados que revelassem os resultados que as empresas respondentes conseguem com a aplicação do programa Seis Sigma. Assim, foram elaboradas questões que indicassem as práticas adotadas pelas empresas para a definição e metas estabelecidas nos projetos Seis Sigma. Por meio de uma questão de "múltipla escolha" foram identificados que os principais critérios para a seleção dos projetos Seis Sigma são:

a) relação com as metas estratégicas da empresa (mais de $90 \%$ );

Tabela 4. Dedicação dos profissionais envolvidos com o programa Seis Sigma.

\begin{tabular}{ccccccc}
\hline $\begin{array}{c}\text { Dedicação exclusiva dos profissionais } \\
\text { ao programa Seis Sigma }\end{array}$ & Master black belts & $\%$ & Black belts & $\%$ & Green belts & \% \\
\hline Sim & 26 & 33,3 & 21 & 26,9 & 0 & 0,0 \\
Não & 13 & 16,7 & 51 & 65,4 & 72 & 92,3 \\
Não responderam & 39 & 50,0 & 6 & 7,7 & 6 & 7,7 \\
\hline
\end{tabular}


b) ganhos financeiros previstos no projeto (cerca de $85 \%) ; \mathrm{e}$

c) aumento na satisfação dos clientes (75\%).

As constatações mencionadas acima são confirmadas por alguns autores que estudam o Seis Sigma, quando afirmam que deve haver critérios adequados para a seleção dos projetos, e que estes sempre se mantenham alinhados com as estratégias das empresas, obedecendo às prioridades de (ANTONY; BANUELAS, 2002; MOTWANI et al., 2004): a) obter lucros; b) ser viável; e c) prever as consequiências do impacto organizacional. Além disso, a orientação dos projetos para atender as exigências dos clientes é imprescindível, e essa condição se viabiliza quando são compreendidos os CTQs (criticals to quality), que são as características críticas para a qualidade (BREYFOGLE III et al., 2001).

Como dado complementar, o levantamento apurou também a quantidade e o tempo médio de duração dos projetos executados pelas empresas. Os dados coletados revelaram que cerca de $23 \%$ das empresas desenvolvem até 5 projetos por ano; perto de $20 \%$ de 6 a 10; aproximadamente $16 \%$ de 11 a $20 ; 9 \%$ de 21 a 30 e aproximadamente $17 \%$ dos respondentes executam acima de 50 projetos.

Uma das questões mais relevantes do levantamento foi sobre os benefícios que o programa Seis Sigma está proporcionando para as empresas. A grande maioria delas, ou seja, aproximadamente $90 \%$ citaram a "redução dos desperdícios" como o principal benefício. Seguindo-se aos benefícios anteriores, o "aumento da produtividade" com quase $85 \%$ e a "diminuição da variabilidade dos processos" com um pouco mais de $80 \%$ foram também citados pelos respondentes. Esta constatação também apresenta um alinhamento com a literatura (ANTONY; BAÑUELAS, 2001; FOLARON, 2003; HAHN et al., 2000; LINDERMAN et al., 2003; PFEIFER et al., 2004; WESSEL; BURCHER, 2004), pois o programa Seis Sigma aplica-se tanto para a melhoria de processos já existentes como também para o desenvolvimento de novos processos industriais, com o objetivo de aumentar a produtividade, diminuir o ciclo de tempo dos processos e o número de itens defeituosos, tendo como conseqüências a diminuição de custos de produção e o aumento da competitividade das empresas.

\subsubsection{Métricas e outros aspectos do programa}

Em relação às escalas adotadas pelas empresas para medir o ganho em qualidade de produtos e de processos na utilização do programa Seis Sigma, o levantamento constatou que, em cerca de $70 \%$ das empresas, a forma adotada para medir o nível de qualidade de produtos e serviços é o ppm (partes por milhão). As demais indicações estão demonstradas na Figura 3.

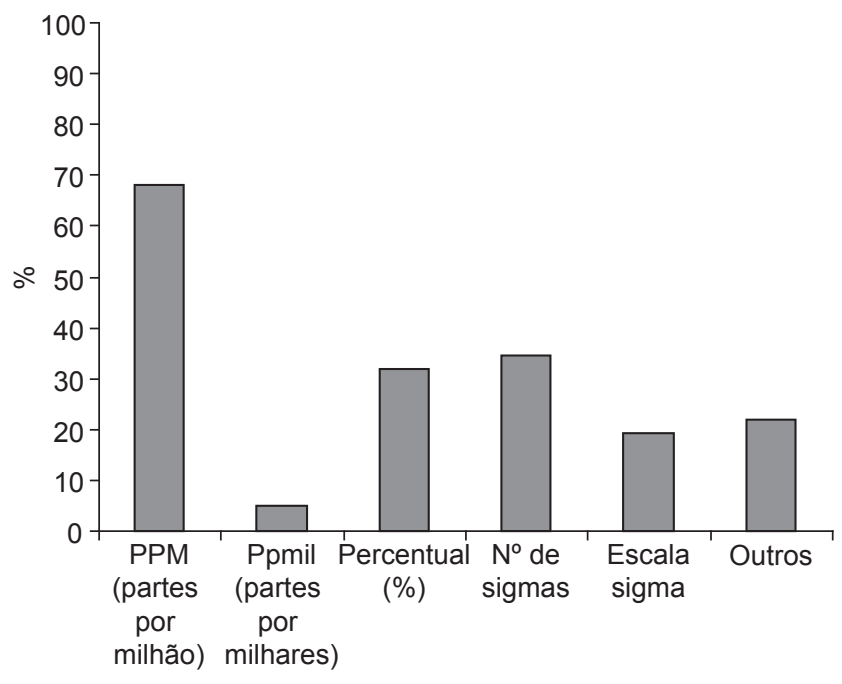

Figura 3. Escala adotada para medir o ganho em qualidade nos produtos e processos.

O resultado anterior também constatou ser similar aos resultados das outras pesquisas realizadas anteriormente. Werkema (2002b) apontou que 55\% das empresas pesquisadas utilizavam o ppm (partes por milhão), enquanto que o outro levantamento (REVISTA FALANDO DE QUALIDADE, 2004) teve uma distribuição eqüitativa entre "ppm" e "\%", com 25\% para cada uma das escalas. Os resultados obtidos também são confirmados por autores tais como; Behara et al. (1995), Eckes (2001) e Goffnet (2004), quando indicaram que as empresas optam preferencialmente pelo "ppm" para medir os ganhos de qualidade conquistados pelo Seis Sigma.

Ainda como dado complementar, o presente levantamento também revelou que mais de $95 \%$ dos respondentes utilizam no tratamento dos dados estatísticos o software denominado Minitab ${ }^{\circledR}$. Além disso, o Microsoft ${ }^{\circledR}$ Excel é usado concomitantemente, em quase $50 \%$ das empresas pesquisadas. Essa constatação ratifica a afirmação de outros autores que propõem que os dados estatísticos sejam processados em softwares adequados ao programa Seis Sigma (HAN; LEE, 2002; HONG; GOH, 2003).

Outra informação de relevância sobre o tema foi quanto à utilização dos chamados "métodos de solução de problemas", que são aplicados nas empresas para a execução dos projetos Seis Sigma. O levantamento confirmou que o DMAIC é o método mais usado na aplicação do programa Seis Sigma (em quase 95\% das empresas respondentes), conforme também afirma Lynch et al. (2003). Outro fato relevante foi a confirmação da utilização de outros métodos, como o DFSS que é utilizado por mais de $25 \%$ das empresas, o DMADV com quase $20 \%$, e o DMEDI usado em pouco mais de $7 \%$ dos respondentes. 


\subsubsection{Ganhos financeiros com o programa}

No que se refere à média dos benefícios financeiros obtidos por projeto, aproximadamente $30 \%$ dos respondentes citaram que conseguiram obter valores que variaram de "R \$ 51 a 100 mil" e cerca de $20 \%$ "acima de R\$ 200 mil". Tais informações corroboram com a literatura (e.g. BEHARA et al., 1995; MARASH, 2000; GOH; XIE, 2004 e MALEYEFF; KRAYENVENGER, 2004), que afirma que se devidamente implementado, o Seis Sigma resulta na conquista de benefícios financeiros.

O levantamento apontou ainda, que com relação aos ganhos financeiros do programa Seis Sigma, aproximadamente $80 \%$ das empresas respondentes confirmam que estes são validados pela área contábil (ou de controladoria) da empresa. Quanto à proporção entre os projetos Seis Sigma aplicados nas áreas produtiva e administrativa, o levantamento indicou que pouco mais de $90 \%$ dos projetos são orientados para área produtiva.

\subsubsection{Continuidade na adoção do programa}

Olevantamento também buscou identificar quais seriam as tendências do Seis Sigma nas empresas respondentes, quanto ao prosseguimento do programa ou a eventual descontinuidade. Os dados observados indicaram que aproximadamente $50 \%$ das empresas pretendem "prosseguir mantendo os investimentos no programa", e apenas $3 \%$ das empresas afirmaram que pretendem "descontinuar temporariamente e retornar o programa no futuro". Sobre essa questão não foram encontrados dados na literatura, mas os outros levantamentos realizados revelaram resultados similares. O trabalho que foi realizado por Werkema (2002b) indicou que 88\% das empresas asseguraram a "ampliação" do programa Seis Sigma em suas atividades e no que foi feito pela revista Falando de Qualidade (2004) apurou 100\%. Contudo, convém manter cautela sobre os dados dos levantamentos anteriores, pois ambos tiveram um número reduzido de respondentes, em especial, o que foi realizado em 2004, que só teve 8 empresas, como já apontado anteriormente.

Finalizando, a apresentação dos dados referentes aos resultados obtidos pelas empresas respondentes que aplicam o Seis Sigma são apresentados, e os aspectos da integração das técnicas, métodos e ferramentas no programa.

\subsection{Integração das técnicas e ferramentas utilizadas no programa Seis Sigma}

As empresas pesquisadas também foram questionadas a respeito das técnicas e ferramentas que são utilizadas nas etapas do método DMAIC. O levantamento se restringiu em apurar tais informações apenas ao DMAIC, uma vez que já havia sido identificado na literatura que o DMAIC é o método mais comumente utilizado pelas empresas que aplicam o Seis Sigma (SNEE, 2000;
BAÑUELAS; ANTONY, 2002; LYNCH et al., 2003; McADAM; LAFFERTY, 2004). A lista submetida ao questionário continha 58 técnicas e ferramentas, e para cada uma deveria ser assinalada a etapa do método na qual a técnica ou a ferramenta era usada. O levantamento revelou que as 10 ferramentas mais utilizadas pelas empresas pesquisadas que aplicam o método DMAIC nos projetos Seis Sigma são: coleta de dados, histograma, diagrama de pareto, brainstorming, cartas de controle, índices de capacidade, fluxograma, mapa de processo, avaliação de sistema de medição e CEP (controle estatístico de processo). Visando maiores esclarecimentos, o Anexo demonstra a utilização das técnicas e ferramentas nas cinco fases do DMAIC.

Comparando-se os resultados deste levantamento com outro realizado por Antony e Bañuelas (2002), que também identificaram as 10 ferramentas mais utilizadas nos projetos Seis Sigma (análise de causa e efeito, cartas de controle, diagrama de pareto, mapa de processo, planejamento de experimentos, FMEA, índices de capacidade, QFD, análise de regressão e teste de hipótese), observa-se que existe coincidência na utilização de quatro ferramentas (cartas de controle, diagrama de pareto, índices de capacidade e mapa de processo).

Os dados coletados no presente trabalho indicaram também, que 8 das 10 técnicas e ferramentas mais usadas no método DMAIC, estão concentradas na etapa "Medir". Justifica-se tal ocorrência, pois nesta fase são aplicadas as ferramentas que medem o desempenho dos processos, que permitem a visualização do estado atual dos mesmos para a definição das metas de aprimoramento (BREYFOGLE III et al., 2001; McADAM; LAFFERTY, 2004).

Contudo, os resultados do presente levantamento quando associados com as 10 ferramentas menos utilizadas no método DMAIC (OCAP, PDPC, operação evolutiva, teste de operação, PERT/COM, teste de mercado, stokeholder, FTA, teste de vida acelerada e stokeholder analysis) não puderam ser comparados, pois não foram encontrados dados na literatura sobre o uso de técnicas e ferramentas, especificamente no método DMAIC. Cabe registrar, porém, que 8 das 10 técnicas e ferramentas menos usadas no método DMAIC também estão concentradas na etapa "Medir". A respeito dessa abordagem, o estudo de Antony e Bañuelas (2002) também apontam as técnicas e ferramentas menos utilizadas nos projetos Seis Sigma (Método Taguchi e Poka-Yoke), que, quando comparadas com o presente levantamento, não são coincidentes. Segundo Antony e Bañuelas (2002), as técnicas e ferramentas "mais poderosas" são menos usadas pelas organizações, o que também foi apontado pela presente pesquisa.

Assim, com a demonstração dos dados relativos à integração das técnicas e ferramentas utilizadas no programa 
Seis Sigma conclui-se a apresentação e a análise dos resultados deste levantamento. A seguir são indicadas as conclusões deste trabalho, bem como algumas perspectivas para trabalhos futuros.

\section{Conclusões e perspectivas para trabalhos futuros}

A abordagem metodológica adotada nessa pesquisa - do tipo survey exploratória-descritiva - se mostrou adequada para atender aos objetivos propostos, que pretendeu ampliar as informações existentes a respeito dos resultados obtidos com a aplicação do programa Seis Sigma no Brasil, e conduzir uma avaliação inicial sobre a eficácia da utilização de tal programa a partir de um conjunto de empresas usuárias. Além disso, em função da relativa e elevada taxa de retorno conseguida neste levantamento, a idoneidade dos respondentes e a diversidade de empresas que participaram da pesquisa, o trabalho possibilitou a obtenção de dados consistentes e a quantificação de uma série de práticas relativas à utilização do programa em organizações que operam no território brasileiro. Sendo assim, pode-se concluir que os objetivos do trabalho foram atingidos, embora existam algumas limitações principalmente relativas à construção do instrumento de coleta de dados, mesmo considerando diversos cuidados na sua elaboração e o universo pesquisado. Se a adoção de faixas nas respostas para algumas questões foi importante para que as empresas expressassem mais facilmente suas respostas, por outro lado restringiu o potencial de obtenção de informações mais exatas. No entanto, considera-se que essa limitação não prejudicou os resultados da pesquisa com intensidade significativa.

Baseado nos resultados, especificamente com base no conjunto de empresas respondentes, conclui-se que uma empresa típica adotou o programa Seis Sigma em 2000, é de grande porte e pertencente ao setor automotivo no estado de São Paulo. A adoção do programa foi estratégica, sendo implantado em quase todas as áreas funcionais da organização, visando obter a redução de desperdícios como principal benefício. A empresa adota a metodologia DMAIC e uma série de técnicas e ferramentas na condução de até 5 projetos por ano, que resultam em retorno financeiro validado pela área contábil que varia de $\mathrm{R} \$ 51$ a 100 mil. Para o futuro, essa empresa típica pretende prosseguir mantendo os investimentos no programa.

\subsection{Perspectivas para pesquisa}

Visando identificar as perspectivas para trabalhos futuros, sugere-se o aprofundamento deste trabalho estendendo o levantamento para uma pesquisa de teste de teoria em Seis Sigma, ou seja, é sugerida a condução de uma survey mais robusta em relação a esse levantamento. Outro aspecto importante é a condução de um levantamento de caráter probabilístico, visando obter um caráter mais abrangente no levantamento. Não obstante, o presente trabalho possibilitou identificar uma consistência na adoção do programa, permitindo concluir que é viável então a adoção de uma amostra mais abrangente para teste de teoria. Além disso, cabe também uma avaliação mais detalhada dos estudos realizados sobre a utilização das técnicas e ferramentas que se integram na rotina das empresas que aplicam o programa Seis Sigma, estabelecendo melhor compreensão dos motivos pelos quais são utilizadas determinadas técnicas e ferramentas nas diferentes etapas dos métodos de execução dos projetos e as razões pelas quais outras técnicas e ferramentas são menos empregadas. Recomenda-se também verificação pormenorizada sobre os benefícios financeiros conquistados com a aplicação do Seis Sigma, visando confirmar se as empresas continuam obtendo ganhos e mantendo o programa como uma estratégia de negócios. Nessas duas últimas perspectivas, uma abordagem metodológica de múltiplos estudos de casos em profundidade poderia ser uma possibilidade de abordagem metodológica a ser adotada.

Ainda que de forma relativamente incipiente, face aos objetivos do presente trabalho e seus resultados, soma-se ainda a oportunidade para possíveis desdobramentos da pesquisa, de modo especial, no que se refere à aplicação do Seis Sigma no desenvolvimento de produtos, além de um estudo que contemple a identificação e análise dos fatores de insucesso na utilização do programa, tema relativamente pouco abordado na literatura sobre o assunto. 


\title{
A study on the application of the Six Sigma programme in Brazil: results of an exploratory-descriptive survey and perspectives for future research
}

\begin{abstract}
The use of the Six Sigma and the techniques associated to the programme have showed results that deserve a more detailed analysis as there are few data published on the application of the Six Sigma in the country The objective of this work is to present the results of an exploratory-descriptive survey, from which the main aim is to identify a series of practices in companies that have adopted the programme. A questionnaire was used as an instrument for data collection with a response rate of approximately 65\% out of the 121 questionnaires sent to the companies. However, the results revealed that the application of the six sigma in Brazil is a reality. However, the program is adopted by large organizations that invest in infrastructure and staff training, enabling them to obtain financial benefits. Finally, the paper points out some perspectives for further work, related to the use of methods and techniques associated with the programme, as well as factors of failure when applying the program.
\end{abstract}

Keywords: Six Sigma. Quality management. Quality improvement. Survey.

\section{Referências bibliográficas}

AEKER, D.; KUMAR, V.; DAY, G. Marketing research. John Wiley \& Sons, Inc. 1995.

ANTONY, J. Some pros and cons of Six Sigma: an academic perspective. The TQM Magazine, v. 16, n. 4, p. 303-306, 2004.

ANTONY, J.; BAÑUELAS, R. A strategy for survival. Manufacturing Engineer, v. 80, n. 3, p. 119-121, 2001.

Key ingredients for the effective implementation of Six Sigma program. Measuring Business Excellence, v. 6, n. 4, p. 20-27, 2002.

ARNHEITER, E. D.; MALEYEFF, J. The integration of lean management and Six Sigma. The TQM Magazine, v. 17, n. 1, p. 5-18, 2005.

BAÑUELAS, R.; ANTONY, J. Critical success factors for the successful implementation of six sigma projects in organizations. The TQM Magazine, v. 14, n. 2, p. 92-99, 2002.

Going from six sigma to design for six sigma: an exploratory study using analytic hierarchy process. The TQM Magazine, v. 15, n. 5, p. 334-344, 2003.

. Six Sigma or design for six sigma? The TQM Magazine, v. 16, n. 4, p. 250-263, 2004.

BARNEY, M. Motorola's Second Generation. Six Sigma Forum Magazine, v. 1. n. 3, p. 13-16, 2002.

BEHARA, R. S.; FONTENOT, G. F.; GRESHAM, A. Customer satisfaction measurement and analysis using six sigma. International Journal of Quality \& Reliability Management, v. 12, n. 3, p. 9-18, 1995.

BLAKESLEE Jr., J. A. Implementing the six sigma solution. Quality Progress, v. 32, n. 1, p. 77-85, 1999.

BREYFOGLE III F. W.; CUPELLO J. M.; MEADOWS, B. Managing Six Sigma: a practical guide to understanding, assessing, and implementing the strategy that yields bottomline success. New York: John Wiley \& Sons, Inc., 2001.

BYRNE, G.; NORRIS, B. Drive Baldrige Level Performance. Six Sigma Forum Magazine, v. 2, n. 3, p. 42-49, 2003.

ECKES, G. The six sigma revolution: how General Electric and others turned process into profits. New York: John Wiley \& Sons, 2001.
EXAME. Melhores e Maiores 2005. São Paulo: Editora Abril. Edição Especial, Julho, 2005.

FALANDO DE QUALIDADE, REVISTA. Pesquisa: A realidade do Seis Sigma no Brasil, Revista Falando de Qualidade, São Paulo: Editora EPSE, ano XIII, n. 144, p. 31-40, 2004.

FOLARON, J. The Evolution of Six Sigma. Six Sigma Forum Magazine, v. 2, n. 4, p. 35-45, 2003.

FORZA, C. Survey research in operations management: a processbased perspective. International Journal of Operations \& Production Management, v. 22, n. 2, p. 152-194, 2002.

GOFFNET, S. P. Understanding Six Sigma Implications for Industry and Education. Journal of Industrial Technology. v. 20 , n. 4, p. 2- 10, 2004.

GOH, T. N.; XIE, M. Improving on the six sigma paradigm. The TQM Magazine, v. 16, n. 4, p. 235-240, 2004.

GUPTA, P. Innovation: the key to a successful project. Six Sigma Forum Magazine, v. 4, n. 4. p. 13-17, 2005.

HAHN, G. J.; DOGONAKSOY, N.; HOERL, R. The evolution of six sigma. Quality Engineering, v. 2, n. 3, p. 317-326, 2000.

HAN, C.; LEE, Y. H. Intelligent integrated plant operation system for six sigma. Annual Reviews Control, v. 26, p. 27-43, 2002.

HARRY, M.; SCHROEDER, R. Six Sigma: the breakthrough management strategy revolutionizing the world's top corporations. New York: Currency, 2000.

HENDERSON, M. H.; EVANS, J. R. Successful implementation of Six Sigma: benchmarking General Electric Company. Benchmarkng An International Journal, v. 7, n. 4, p. 260-281, 2000.

HENDRICKS, C. A.; KELBAUGH, R. Implementing Six Sigma at GE. The Journal of Quality and Participation, v. 21, n. 4 p. 48-53, 1998.

HOERL, R. W. Six Sigma and the future of the quality profession. IEEE Engineering Management, fall, p. 87-94, 1998.

Six Sigma Black Belts: what do they need to know? Journal of Quality Technology, v. 33, n. 4, p. 35-42, 2001.

HONG, G. Y.; GOH, T. N. Six Sigma in software quality. The TQM Magazine, v. 15, n. 6, p. 364-373, 2003. 
INGLE, S.; ROE, W. Six sigma black belt implementation. The TQM Magazine, v. 13, n. 4, p. 273-280, 2001

KLEFSJÖ, B.; WIKLUND, N.; EDEGMAN, R. L. Six Sigma seen as a methodology for total quality management. Measuring Business Excellence, v. 5, n. 1, p. 31-35, 2001.

LINDERMAN, K. et al. Six Sigma: a goal-theoretic perspective. Journal of Operations Management, v. 3, n. 21, p. 193-203, 2003.

LYNCH D. P.; BERTOLINE, S.; CLOUTIER, E. How to scope DMAIC projects. Quality Progress, v. 36, n. 1, p. 37-41, 2003.

MALEYEFF, J.; KRAYENVENGER, D. E. Goal setting with Six Sigma mean shift determination. Aircraft Engineering and Aerospace Technology, v. 76, n. 6, p. 577-583, 2004.

MALHOTRA, N. K. Pesquisa de marketing: uma orientação aplicada. Porto Alegre: Bookman, 2001.

MALHOTRA, N. K; GROVER, V. An assessment of survey research in POM: from constructs to theory. Journal of Operations Management, v. 16, n. 17, p. 407-425, 1998.

MARASH, S. A. Six Sigma: Business Results Though Innovation. In: ANNUAL QUALITY CONGRESS OF THE AMERICAN SOCIETY FOR QUALITY, 54., Proceedings... Indianapolis: Indiana, p. 627-630, May, 2000.

MARCONI, M. D. A.; LAKATOS, E. M. Técnicas de pesquisa: planejamento e execução de pesquisas, amostragens e técnicas de pesquisas, elaboração, análise e interpretação de dados. 3. ed. São Paulo: Atlas, 1996.

MATTAR, F. N. Pesquisa de marketing: edição compacta. São Paulo: Atlas, 1996.

McADAM, R.; LAFFERTY, B. A multilevel case study critique of Six Sigma: statistical control of strategic change? International Journal of Operations \& Production Management. v. 24, n. 5, p. 530-549, 2004.

MOTWANI, J; KUMAR, A.; ANTONY, J. A business process change framework for examining the implementation of six sigma: a case study of Dow Chemicals. The TQM Magazine, v. 16, n. 4, p. 273-283, 2004.

MUNRO, R. A. Linking Six Sigma with QS- 9000. Quality Progress, v. 33, n. 5, p. 47-53, 2000.

PANDE, P. S.; NEUMAN, R. P.; CAVANAGH, R. R. The six sigma way: how GE, Motorola, and other top companies are honing their performance. New York: McGraw-Hill, 2000.

PEREZ-WILSON, M. Six Sigma: understanding the concept, implications and challenges. Scottsdale: Advanced Systems Consultants, 1999.

PFEIFER, T.; REISSIGER, W.; CANALES, C. Integrating six sigma with quality management systems. The TQM Magazine, v. 16, n. 4, p. 241-249, 2004.

RAISINGHANI, M.; ETTE, H.; PIERCE, R.; CANNON, G.; DARIPLAY, P. Six Sigma: concepts, tools, and applications. Industrial Management \& Data Systems, v. 105, n. 4, p. 491-505, 2005.

SENAPATI, S. R. Six Sigma: myths and realities. International Journal of Quality \& Reliability Management, v. 21, n. 6, p. 683-690, 2004.

SNEE, R. D. Impact of Six Sigma on Quality Engineering. Quality Engineering, v. 12, n. 3, p. 31-34, 2000.

THEVNIN, C. Effective management commitment enhances six sigma success. Handbook of Business Strategy, v. 5, n. 1, p. 195-200, 2004.

WERKEMA, M. C. C. Criando a Cultura Seis Sigma. Rio de Janeiro: Qualitymark, v. 1, 2002a.

. Report Seis Sigma. São Paulo: Editora EPSE, 2002b.

WESSEL, G.; BURCHER, P. Six Sigma for small and mediumsized enterprises. The TQM Magazine, v. 16, n. 4, p. 264-272, 2004.

WIPER, B.; HARRISON, A. Deployment of Six Sigma methodologies in Human Resource function: A case study. Total Quality Management, v. 11, n. 4, p. 720-728, 2000.

YOUNG, A. Six Sigma: creating an advantage competitive. The Virtual Strategist, p. 38-41, 2001.

\section{Anexo - Técnicas e Ferramentas utilizadas nas etapas do método DMAIC (\% dos respondentes da pesquisa).}

\begin{tabular}{lllllllc}
\hline \multicolumn{1}{c}{ Técnicas e ferramentas } & \multicolumn{7}{c}{ Etapa do método DMAIC } \\
\cline { 2 - 8 } & Definir & Medir & Analisar & Melhorar & Controlar & Todas & Ranking \\
\hline Técnicas de coleta de dados & 55,13 & 89,74 & 46,15 & 34,62 & 34,62 & 52,05 & 1 \\
Histograma & 33,33 & 74,36 & 67,95 & 28,21 & 37,18 & 48,21 & 2 \\
Diagrama de pareto & 57,69 & 64,10 & 64,10 & 25,64 & 26,92 & 47,69 & 3 \\
Brainstorming & 65,38 & 38,46 & 61,54 & 44,87 & 17,95 & 45,64 & 4 \\
Carta de controle & 19,23 & 50,00 & 50,00 & 29,49 & 75,64 & 44,87 & 5 \\
Índices de capacidade & 26,92 & 57,69 & 47,44 & 39,74 & 48,72 & 44,10 & 6 \\
Fluxograma & 60,26 & 51,28 & 46,15 & 34,62 & 20,51 & 42,56 & 7 \\
Mapa de processo & 55,13 & 46,15 & 50,00 & 34,62 & 16,67 & 40,51 & 8 \\
Avaliação de sistemas de medição/inspeção & 14,10 & 83,33 & 38,46 & 33,33 & 25,64 & 38,97 & 9 \\
Controle estatístico de processo & 15,38 & 41,03 & 37,18 & 28,21 & 70,51 & 38,46 & 10 \\
Mapeamento do processo & 55,13 & 46,15 & 34,62 & 34,62 & 17,95 & 37,69 & 11 \\
FMEA & 19,23 & 32,05 & 57,69 & 50,00 & 28,21 & 37,44 & 12 \\
Mensuração de defesa & 23,08 & 61,54 & 25,64 & 24,36 & 30,77 & 33,08 & 13 \\
\hline
\end{tabular}




\section{Anexo. Continuação...}

\begin{tabular}{|c|c|c|c|c|c|c|c|}
\hline \multirow[t]{2}{*}{ Técnicas e ferramentas } & \multicolumn{7}{|c|}{ Etapa do método DMAIC } \\
\hline & Definir & Medir & Analisar & Melhorar & Controlar & Todas & Ranking \\
\hline Mapa de raciocínio & 37,18 & 35,90 & 30,77 & 30,77 & 25,64 & 32,05 & 14 \\
\hline Diagrama de causa e efeito & 25,64 & 38,46 & 70,51 & 23,08 & 2,56 & 32,05 & 15 \\
\hline Análise econômica & 60,26 & 19,23 & 34,62 & 23,08 & 21,79 & 31,79 & 16 \\
\hline Técnicas de amostragem & 12,82 & 66,67 & 32,05 & 19,23 & 25,64 & 31,28 & 17 \\
\hline Boxplot & 19,23 & 43,59 & 62,82 & 19,23 & 7,69 & 30,51 & 18 \\
\hline Análise do tempo de ciclo & 23,08 & 43,59 & 48,72 & 17,95 & 16,67 & 30,00 & 19 \\
\hline Análise de variância & 8,97 & 28,21 & 75,64 & 23,08 & 8,97 & 28,97 & 20 \\
\hline Voz do cliente & 65,38 & 23,08 & 19,23 & 15,38 & 20,51 & 28,72 & 21 \\
\hline Folha de verificação & 12,82 & 48,72 & 26,92 & 17,95 & 37,18 & 28,72 & 22 \\
\hline Estratificação & 35,90 & 46,15 & 44,87 & 11,54 & 2,56 & 28,21 & 23 \\
\hline Análise de causa raiz & 25,64 & 24,36 & 74,36 & 8,97 & 3,85 & 27,44 & 24 \\
\hline Testes de hipóteses & 0,00 & 14,10 & 71,79 & 33,33 & 11,54 & 26,15 & 25 \\
\hline Diagrama de dispersão & 6,41 & 30,77 & 69,23 & 14,10 & 7,69 & 25,64 & 26 \\
\hline Planejamento de experimentos & 2,56 & 8,97 & 50,00 & 56,41 & 6,41 & 24,87 & 27 \\
\hline Análise de regressão & 6,41 & 16,67 & 79,49 & 15,38 & 3,85 & 24,36 & 28 \\
\hline $5 \mathrm{~W} 2 \mathrm{H}$ & 24,36 & 19,23 & 26,92 & 34,62 & 16,67 & 24,36 & 29 \\
\hline Gráfico seqüencial & 23,08 & 43,59 & 25,64 & 10,26 & 19,23 & 24,36 & 30 \\
\hline$P O K A-Y O K E$ & 5,13 & 3,85 & 8,97 & 50,00 & 51,28 & 23,85 & 31 \\
\hline Procedimento operacional padrão & 7,69 & 8,97 & 12,82 & 42,31 & 44,87 & 23,33 & 32 \\
\hline Matriz de priorização & 24,36 & 25,64 & 32,05 & 30,77 & 2,56 & 23,08 & 33 \\
\hline QFD & 37,18 & 24,36 & 26,92 & 15,38 & 5,13 & 21,79 & 34 \\
\hline Diagrama árvore & 25,64 & 21,79 & 42,31 & 11,54 & 2,56 & 20,77 & 35 \\
\hline Project charter & 61,54 & 7,69 & 7,69 & 10,26 & 14,10 & 20,26 & 36 \\
\hline SIPOC & 61,54 & 16,67 & 7,69 & 2,56 & 3,85 & 18,46 & 37 \\
\hline Análise de tempo de falhas & 8,97 & 25,64 & 43,59 & 7,69 & 5,13 & 18,21 & 38 \\
\hline Simulação & 1,28 & 8,97 & 26,92 & 47,44 & 6,41 & 18,21 & 39 \\
\hline Diagrama de Gantt & 25,64 & 16,67 & 17,95 & 20,51 & 8,97 & 17,95 & 40 \\
\hline Mapa de produto & 25,64 & 23,08 & 19,23 & 15,38 & 5,13 & 17,69 & 41 \\
\hline Análise multivariada & 5,13 & 12,82 & 51,28 & 10,26 & 1,28 & 16,15 & 42 \\
\hline Diagrama de relações & 6,41 & 17,95 & 35,90 & 12,82 & 3,85 & 15,38 & 43 \\
\hline Diagrama de afinidades & 12,82 & 15,38 & 33,33 & 8,97 & 2,56 & 14,62 & 44 \\
\hline Técnicas estat.de prev. séries temporais & 7,69 & 12,82 & 26,92 & 11,54 & 14,10 & 14,62 & 45 \\
\hline Relatório de anomalias & 10,26 & 14,10 & 12,82 & 16,67 & 19,23 & 14,62 & 46 \\
\hline Carta multi-van & 3,85 & 10,26 & 32,05 & 10,26 & 10,26 & 13,33 & 47 \\
\hline Diagrama de matriz & 8,97 & 19,23 & 24,36 & 12,82 & 0,00 & 13,08 & 48 \\
\hline Stokeholder analysis & 29,49 & 7,69 & 6,41 & 8,97 & 3,85 & 11,28 & 49 \\
\hline Teste de vida acelerada & 0,00 & 11,54 & 25,64 & 10,26 & 5,13 & 10,51 & 50 \\
\hline FTA & 2,56 & 6,41 & 30,77 & 7,69 & 3,85 & 10,26 & 51 \\
\hline Stokeholder & 29,49 & 6,41 & 1,28 & 6,41 & 3,85 & 9,49 & 52 \\
\hline Teste de mercado & 5,13 & 11,54 & 14,10 & 11,54 & 5,13 & 9,49 & 53 \\
\hline PERT/COM & 8,97 & 8,97 & 3,85 & 14,10 & 2,56 & 7,69 & 54 \\
\hline Teste de operação & 2,56 & 5,13 & 14,10 & 14,10 & 2,56 & 7,69 & 55 \\
\hline Operação evolutiva & 2,56 & 5,13 & 11,54 & 15,38 & 2,56 & 7,44 & 56 \\
\hline PDPC & 3,85 & 7,69 & 6,41 & 10,26 & 1,28 & 5,90 & 57 \\
\hline OCAP & 0,00 & 3,85 & 5,13 & 5,13 & 12,82 & 5,38 & 58 \\
\hline
\end{tabular}

10 Técnicas e ferramentas mais utilizadas nas etapas do método DMAIC; e $\square 10$ técnicas e ferramentas menos utilizadas nas etapas do método DMAIC. 


\section{Sobre os autores}

\section{João Marcos Andrietta}

Programa de Pós-Graduação de Engenharia de Produção, Faculdade de Engenharia, Arquitetura e Urbanismo, Universidade Metodista de Piracicaba - UNIMEP, Rod. SP 306, Km 1, CEP 13450-000, Santa Bárbara d'Oeste, SP, Brasil, e-mail: j.m.andrietta@uol.com.br

\section{Paulo Augusto Cauchick Miguel}

Programa de Pós-Graduação de Engenharia de Produção, Núcleo de Gestão da Qualidade \& Metrologia, Faculdade de Engenharia, Arquitetura e Urbanismo, Universidade Metodista de Piracicaba - UNIMEP, Rod. SP 306, Km 1, CEP 13450-000 Santa Bárbara d'Oeste, SP, Brasil,

e-mail: pamiguel@unimep.br

Universidade de São Paulo, Escola Politécnica, Departamento de Engenharia de Produção, Av. Prof Almeida Prado, Trav. 2, n 128, $2^{\circ}$ andar, Cidade Universitária, CEP 05508-900, São Paulo, SP, Brasil, e-mail: paulo.miguel@poli.usp.br

Agradecimentos: Os autores agradecem aos revisores pelas sugestões de aperfeiçoamento do artigo, às empresas que responderam o questionário, ao Prof. Nelson Maestrelli pelo auxílio na revisão das versões do questionário e ao CNPq (processo 474160/2004-1) pelo apoio por meio de projeto de pesquisa do Edital Universal 2005, coordenado pela Profa. Marly Monteiro de Carvalho.

Recebido em 03/4/2006

Aceito em 04/5/2007 
